\title{
Vulvar Keratoacanthoma
}

National Cancer Institute

\section{Source}

National Cancer Institute. Vulvar Keratoacanthoma. NCI Thesaurus. Code C128167.

A keratoacanthoma that arises from the vulva. It grows rapidly and may regress spontaneously. In some cases it is associated with prior trauma. Many cases diagnosed as keratoacanthomas show some degree of atypia and metastases have been reported. In such cases, the neoplasm is referred as squamous cell carcinoma, keratoacanthoma type. 